\title{
The Changing Profile of ECS Teachers
}

\author{
Steven McGee \\ The Learning Partnership \\ Chicago, Illinois \\ mcgee@lponline.net \\ Andrew M. Rasmussen \\ Chicago Public Schools \\ Chicago, Illinois \\ arasmussen@cps.edu
}

\author{
Lucia Dettori \\ DePaul University \\ Chicago, Illinois \\ lucia@cdm.depaul.edu \\ Dale F. Reed \\ University of Illinois at Chicago \\ Chicago, Illinois \\ reed@uic.edu
}

\author{
Ronald I. Greenberg \\ Loyola University Chicago \\ Chicago, Illinois \\ rig@cs.luc.edu \\ Don Yanek \\ Chicago Public Schools \\ Chicago, Illinois \\ dgyanek@cps.edu
}

\begin{abstract}
This study compares the characteristics and professional development (PD) experiences between teachers who began teaching Exploring Computer Science before and after the enactment of a CS graduation requirement in the Chicago Public Schools. The postrequirement teachers were less likely to have a CS background, but their experience in the ECS PD and their level of confidence at the end of the PD were equivalent to the early adopters.
\end{abstract}

\section{CCS CONCEPTS}

- Social and professional topics $\rightarrow \mathrm{K}-12$ education.

\section{KEYWORDS}

Professional development; Exploring Computer Science

\section{INTRODUCTION}

A key strategy for broadening CS participation in the Chicago Public Schools (CPS) has been the enactment of a high school CS graduation requirement in 2016 [1]. The Exploring Computer Science (ECS) curriculum and professional development (PD) program [2] serves as a core foundation for supporting enactment of this policy. The PD program has been successful at preparing CPS teachers to support student success in the ECS course [3]. The work leading to establishment of the graduation requirement began with a teacher-led initiative bringing together CPS teachers, CPS administrators, educational researchers, and university faculty. The partnership, which became known as the Chicago Alliance for Equity in Computer Science (CAFÉCS), brought the ECS curriculum and PD program to Chicago [4]. In the first two school years of the PD program (2012-2014), 95 teachers volunteered to participate in the ECS PD. In the three years since the introduction of the graduation requirement (2016-2019), 219 teachers have participated in the ECS PD, many of whom were assigned by their principal. What are the differences in the characteristics and perceptions of early-adopter and post-requirement teachers?

Permission to make digital or hard copies of part or all of this work for personal or classroom use is granted without fee provided that copies are not made or distributed for profit or commercial advantage and that copies bear this notice and the full citation on the first page. Copyrights for third-party components of this work must be honored. For all other uses, contact the owner/author(s).

SIGCSE '20, March 11-14, 2020, Portland, OR, USA

(c) 2020 Copyright held by the owner/author(s)

ACM ISBN 978-1-4503-6793-6/20/03.

https://doi.org/10.1145/3328778.3372679

\section{METHODS / RESULTS}

At the beginning of the weeklong summer ECS workshop, teachers completed a background survey asking about CS background, teaching experience, gender, and race. At the end of the week, teachers completed a feedback survey asking about workshop satisfaction and confidence in implementing ECS. The results indicate that more than half of the early adopters had a background in CS (53\%) as compared to about one-quarter for post-requirement teachers (24\%). As a consequence, the early adopters had more years of prior experience teaching CS (4.1 years) relative to post-requirement teachers (1.8 years), even through the overall years of teaching experience of early adopters (10.1 years) and post-requirement teachers (10.4 years) was similar. The composition of the early adopters relative to the post-requirement teachers by race ( $47 \%$ minority vs $39 \%$ ) and gender ( $51 \%$ vs $47 \%$ female) was similar. Despite differences in CS background and motivation for teaching the class, there were no significant differences in teachers' levels of satisfaction with the workshop experience (4.8/5 vs $4.6 / 5)$ nor in their post-workshop level of confidence to teach ECS (3.4/4 vs $3.3 / 4)$.

\section{CONTRIBUTION}

ECS has primarily been implemented as an elective course with volunteer teachers. This study provides evidence that teachers who are assigned to participate can still have a positive PD experience.

\section{ACKNOWLEDGMENTS}

This research was supported by National Science Foundation grant numbers CNS-1842085, CNS-1738572, CNS-1738776, CNS-1738691, CNS-1738515, DRL-1640215, CNS-1542971, and CNS- 1543217.

\section{REFERENCES}

[1] Lucia Dettori, Ronald I. Greenberg, Steven McGee, Dale Reed, Brenda Wilkerson, and Don Yanek. 2018. CS as a Graduation Requirement: Catalyst for Systemic Change. In SIGCSE '18. Association for Computing Machinery, 406-407. Baltimore, MD. https://doi.org/10.1145/3159450.3159646.

[2] Joanna Goode, Jane Margolis, and Gail Chapman. 2014. Curriculum is Not Enough: The Educational Theory and Research Foundation of the Exploring Computer Science Professional Development Model. In SIGCSE '14. Association for Computing Machinery, 493-498.

[3] Steven McGee, Ronald I. Greenberg, Lucia Dettori, Andrew M. Rasmussen, Randi McGee-Tekula, Jennifer Duck, and Erica Wheeler. 2018. An Examination of Factors Correlating with Course Failure in a High School Computer Science Course. Technical Report 5. The Learning Partnership. https://ecommons.luc.edu/cs_facpubs/205.

[4] Dale Reed, Brenda Wilkerson, Don Yanek, Lucia Dettori, and Jeff Solin. 2015. How Exploring Computer Science (ECS) Came to Chicago. ACM Inroads 6, 3 (Sept. 2015), 75-77. 